\title{
Relation between attempted suicide and suicide rates among young people in Europe
}

\author{
K Hawton, E Arensman, D Wasserman, A Hultén, U Bille-Brahe, T Bjerke, P Crepet, \\ E Deisenhammer, A Kerkhof, D De Leo, K Michel, A Ostamo, A Philippe, I Querejeta, \\ E Salander-Renberg, A Schmidtke, B Temesváry
}

In contrast with attempted suicide, suicide Abstract
Study objective-To determine if there are
associations between rates of suicide and
attempted suicide in $15-24$ year olds in
different countries in Europe.
Design-Attempted suicide rates were
based on data collected in centres in
Europe between 1989 and 1992 as part of
the WHO/EURO Multicentre Study of
Parasuicide. Comparison was made with
both national suicide rates and local
suicide rates for the areas in which the
attempted suicide monitoring centres are
based.
Setting-15 centres in 13 European coun-
tries. Patients-Young people aged 15-24 years who had taken overdoses or deliberately injured themselves and been identified in health care facilities.

Main results-There were positive correlations (Spearman rank order) between rates of attempted suicide and suicide rates in both sexes. The correlations only reached statistical significance for male subjects: regional suicide rates, $r=0.65, p$ $<0.02$; national suicide rates, $r=0.55$, $\mathrm{p}<$ 0.02 .

Conclusions-Rates of attempted suicide and suicide in the young covary. The recent increase in attempted suicide rates in young male subjects in several European countries could herald a further increase in suicide rates.

(F Epidemiol Community Health 1998;52:191-194)

Suicidal behaviour is increasingly becoming a phenomenon associated with young people. Findings from the current WHO/EURO Multicentre Study of Parasuicide indicate that while there are pronounced differences between attempted suicide rates in different centres, in most of the 16 participating centres in 13 European countries the highest rates are in 15-24 year old female young adults. ${ }^{1-3}$ Rates are also relatively high in young male subjects, although peak rates are more usually in the 25-34 year age group. There is evidence from some countries that attempted suicide rates in young people have increased since the mid 1980 s. $^{45}$ There has also been a considerable narrowing of the female to male ratio of rates in the young, the usual marked female excess becoming steadily less pronounced, largely because of a disproportionate increase in male rates. $^{25}$ rates are generally higher in male subjects than female subjects, and the highest rates of suicide are usually found in older age groups. ${ }^{6}$ There have, however, been important changes in this pattern in recent years, many countries having experienced a noticeable rise in suicide rates in young male subjects. Suicide has become a leading cause of death in the young, and in some countries (for example, Sweden) it is now the most common cause of death in 15-24 year olds. In other countries (for example, England and Wales) it is second only to road traffic accidents.

While there are considerable differences between attempted suicide and suicide in terms of the characteristics of the people involved and their motives, the two phenomena are also strongly linked. Thus, people who attempt suicide are at high risk of eventual suicide and nearly half of those who kill themselves have a history of previous attempts. ${ }^{7}$ What is not known is the extent to which rates of suicide and attempted suicide are correlated, especially at the international level. In this paper we examine the statistical relation between attempted suicide and suicide rates in 15-24 year olds across European countries. The data on attempted suicide were derived from the epidemiological part of the WHO/ EURO Multicentre Study of Parasuicide. ${ }^{1} 2389$

\section{Method}

ATTEMPTED SUICIDE DATA

The epidemiological part of the WHO/EURO Multicentre Study of Parasuicide started in 1989. The data for this study were collected in 15 research centres in 13 European countries (table 1). In most of the centres the monitoring study is ongoing. The results reported here concern the first four years of the study, 19891992.

In each of the participating centres data are collected on suicide attempts by residents of the centre's catchment area aged 15 years and over, who are treated by health care services in the area. A standard registration form is used to obtain information on demographic variables and characteristics of the suicide attempt. In some centres, the registration of suicide attempts has been incomplete because of nonresponse and missing information, and therefore the number of actual suicide attempts was estimated by means of extrapolation from the available information. ${ }^{3}$ In each participating centre the monitoring study of attempted suicide was approved by a local ethics committee. 
Table 1 Average attempted suicide and suicide rates per 100000 population (regional and national) in female subjects in age groups 15-24, 15-19, and 20-24 years

\begin{tabular}{|c|c|c|c|c|c|c|c|c|c|c|}
\hline Centre & Country & $\begin{array}{l}\text { Attempted } \\
\text { suicide rates } \\
15-24\end{array}$ & $\begin{array}{l}\text { Attempted } \\
\text { suicide rates } \\
15-19\end{array}$ & $\begin{array}{l}\text { Attempted } \\
\text { suicide rates } \\
20-24\end{array}$ & $\begin{array}{l}\text { Suicide rates } \\
\text { regional } \\
15-24\end{array}$ & $\begin{array}{l}\text { Suicide rates } \\
\text { national } \\
15-24\end{array}$ & $\begin{array}{l}\text { Suicide rates } \\
\text { regional } \\
15-19\end{array}$ & $\begin{array}{l}\text { Suicide rates } \\
\text { national } \\
15-19\end{array}$ & $\begin{array}{l}\text { Suicide rates } \\
\text { regional } \\
20-24\end{array}$ & $\begin{array}{l}\text { Suicide rates } \\
\text { national } \\
20-24\end{array}$ \\
\hline Cergy-Pontoise & France & 766 & 893 & 652 & $-\dagger$ & 4 & $-\dagger$ & 一 & $-\dagger$ & - \\
\hline Oxford & $\begin{array}{l}\text { United } \\
\text { Kingdom }\end{array}$ & 629 & 795 & 528 & 2 & 2 & 2 & 1 & 2 & 3 \\
\hline Helsinki & Finland & 347 & 311 & 368 & 18 & 8 & 2 & 5 & 20 & 11 \\
\hline Szeged & Hungary & 323 & 503 & 222 & 48 & 6 & 36 & 5 & 55 & 8 \\
\hline Stockholm & Sweden & $299(261)^{\star}$ & $308(267)^{\star}$ & $289(255)^{\star}$ & 9 & 7 & 3 & 5 & 14 & 7 \\
\hline Bern & Switzerland & 267 & 266 & 267 & 8 & 7 & 9 & 4 & 8 & 9 \\
\hline Sor-Trondelag & Norway & 235 & 250 & 289 & $-\dagger$ & 6 & $-\dagger$ & 7 & $-\dagger$ & 5 \\
\hline Umea & Sweden & $220(261)^{\star}$ & $227(267)^{\star}$ & $216(255)^{\star}$ & 0 & 7 & 0 & 5 & 0 & 7 \\
\hline Wurzburg & Germany & 208 & 336 & 139 & 7 & 4 & 7 & 3 & 6 & 5 \\
\hline Odense & Denmark & 191 & 192 & 187 & 2 & 4 & 0 & 2 & 4 & 5 \\
\hline Innsbruck & Austria & 187 & 241 & 147 & 5 & 7 & 3 & 5 & 5 & 8 \\
\hline Leiden & $\begin{array}{l}\text { the } \\
\text { Netherlands }\end{array}$ & 172 & 188 & 162 & 3 & 5 & $-\dagger$ & 4 & $-\dagger$ & 9 \\
\hline Emilia-Romagna & Italy & $151(151)^{\star}$ & 158 & 146 & 2 & 2 & $-\dagger$ & - & $-\dagger$ & $-\dagger$ \\
\hline Padova & Italy & $150(151)^{\star}$ & 181 & 123 & 3 & 2 & 3 & - & 3 & 一 \\
\hline Guipuzcoa & Spain & 99 & 125 & 71 & $-\dagger$ & 2 & $-\dagger$ & 1 & $-\dagger$ & 2 \\
\hline
\end{tabular}

^ For countries where two centres participated, average attempted suicide rates were computed to make a comparison with the national suicide rates (for Italy only for the age group 15-24 years); † no regional suicide data were available for three centres for 15-24 year olds and for five centres for 15-19 and 20-24 year olds; $\ddagger$ for two countries no national suicide data were available.

Attempted suicide was defined according to the proposed ICD-10 definition: "An act with non-fatal outcome, in which an individual deliberately initiates a non-habitual behaviour that, without intervention from others, will cause self-harm, or deliberately ingests a substance in excess of the prescribed or generally recognised therapeutic dosage, and which is aimed at realising changes which the subject desired via the actual or expected physical consequences".

On the basis of the monitoring data over a period of only four years it is difficult to examine trends. Therefore, average attempted suicide rates were computed for the period 19891992, for female and male subjects separately, in the age groups $15-24,15-19$, and 20-24 years. For most centres average attempted suicide rates were computed on the basis of the four year data. Exceptions (and the years on which average annual rates could be based) were Bern (1989-1990), Cergy-Pontoise (1989-1991), and Guipuzcoa (1989-1991).

\section{SUICIDE STATISTICS}

Regional and national suicide rates were computed on the basis of data provided by the centres and by using national statistics. ${ }^{10}{ }^{11}$ For most centres average regional and national suicide rates were computed for male and female subjects on the basis of four year data (1989-1992). No regional suicide data were available for all three age groups (15-24, 15-19, and 20-24 years) for two centres, Cergy-Pontoise and Guipuzcoa. No regional suicide data were available in five year age bands (15-19 and 20-24 years) for five centres, Cergy-Pontoise, Sor-Trondelag, Leiden, Emilia-Romagna, and Guipuzcoa. No national suicide data in five year age bands were available for three centres, Cergy-Pontoise (France), Padova and Emilia-Romagna (Italy).

STATISTICAL ANALYSIS

Correlations between attempted suicide and suicide rates were calculated by means of Spearman rank order correlation coefficients. In two countries, Italy and Sweden, two research centres were participating. Therefore, the rank order correlations between attempted suicide rates and national suicide rates were based on average attempted suicide rates of the two centres. For the centres Padova and Emilia-Romagna rank order correlations could only be calculated for the age group 15-24 years.

\section{Results}

ATTEMPTED SUICIDE AND SUICIDE RATES IN FEMALE SUBJECTS

The attempted suicide and suicide rates for female subjects in the age groups 15-24, 15-19, and 20-24 years are shown in table 1 , with the centres ranked according to the attempted suicide rates in the age group 15-24 years. The highest female attempted suicide rate in the age group 15-24 years was found in Cergy-Pontoise (766 per 100000 ), and the lowest in Guipuzcoa (99 per 100 000), with more than a sevenfold difference between them. For the age groups 15-19 years and 20-24 years, in 12 of the 15 centres the highest attempted suicide rates were found among those aged $15-19$ years.

With regard to suicide rates in female subjects (table 1), extremely high regional rates for 15-24 year olds and for the 15-19 and 20-24 year age bands were found in Szeged, but these were not representative of the national Hungarian suicide rates. Relatively high regional rates were also found in 15-24 year olds in Helsinki, Finland having the highest national rate. The highest national rates in 15-19 year olds were in Norway and the highest in 20-24 year olds were in Finland.

\section{ATTEMPTED SUICIDE AND SUICIDE RATES FOR}

MALE SUBJECTS

The attempted suicide rates in male subjects were lower than those for female subjects, except for Helsinki where male rates were lower than those of females in the age group 15-19 years (tables 1 and 2). The highest male attempted suicide rate in the age group 15-24 years was found in Helsinki (372 per 100 000), and the lowest rate in Emilia-Romagna (54 per 
Table 2 Average attempted suicide and suicide rates per 100000 population (regional and national) in male subjects in age groups 15-24, 15-19, and 20-24 years

\begin{tabular}{|c|c|c|c|c|c|c|c|c|c|c|}
\hline Centre & Country & $\begin{array}{l}\text { Attempted } \\
\text { suicide rates } \\
15-24\end{array}$ & $\begin{array}{l}\text { Attempted } \\
\text { suicide rates } \\
15-19\end{array}$ & $\begin{array}{l}\text { Attempted } \\
\text { suicide rates } \\
20-24\end{array}$ & $\begin{array}{l}\text { Suicide rates } \\
\text { regional } \\
15-24\end{array}$ & $\begin{array}{l}\text { Suicide rates } \\
\text { national } \\
15-24\end{array}$ & $\begin{array}{l}\text { Suicide rates } \\
\text { regional } \\
15-19\end{array}$ & $\begin{array}{l}\text { Suicide rates } \\
\text { national } \\
15-19\end{array}$ & $\begin{array}{l}\text { Suicide rates } \\
\text { regional } \\
20-24\end{array}$ & $\begin{array}{l}\text { Suicide rates } \\
\text { national } \\
20-24\end{array}$ \\
\hline Helsinki & Finland & 372 & 254 & 447 & 42 & 45 & 25 & 32 & 36 & 57 \\
\hline Cergy-Pontoise & France & 337 & 283 & 386 & $-\dagger$ & 14 & $-\dagger$ & - & $-\dagger$ & - \\
\hline Oxford & $\begin{array}{l}\text { United } \\
\text { Kingdom }\end{array}$ & 314 & 307 & 319 & 11 & 11 & 5 & 5 & 16 & $16^{\circ}$ \\
\hline Szeged & Hungary & 253 & 200 & 293 & 44 & 22 & 50 & 14 & 39 & 30 \\
\hline Odense & Denmark & 176 & 94 & 251 & 11 & 13 & 4 & 7 & 17 & 19 \\
\hline Sor-Trondelag & Norway & 169 & 110 & 224 & $-\dagger$ & 26 & $-\dagger$ & 18 & $-\dagger$ & 33 \\
\hline Bern & Switzerland & 153 & 76 & 207 & 29 & 25 & 23 & 14 & 33 & 34 \\
\hline Stockholm & Sweden & $148(129)^{\star}$ & $92(79)^{\star}$ & $200(175)^{\star}$ & 12 & 16 & 6 & 9 & 17 & 21 \\
\hline Umea & Sweden & $114(129)^{\star}$ & $67(79)^{\star}$ & $151(175)^{\star}$ & 15 & 16 & 0 & 9 & 22 & 21 \\
\hline Wurzburg & Germany & 113 & 93 & 125 & 9 & 15 & 15 & 10 & 6 & 18 \\
\hline Innsbruck & Austria & 105 & 61 & 137 & 22 & 26 & 15 & 17 & 27 & 32 \\
\hline Leiden & $\begin{array}{l}\text { the } \\
\text { Netherlands }\end{array}$ & 101 & 46 & 118 & 11 & 11 & $-\dagger$ & 8 & $-\dagger$ & 25 \\
\hline Guipuzcoa & Spain & 62 & 30 & 96 & $-\dagger$ & 7 & $-\dagger$ & 1 & $-\dagger$ & 7 \\
\hline Padova & Italy & $55(55)^{\star}$ & 19 & 81 & 1 & 6 & 4 & 一 & 0 & - \\
\hline Emilia-Romagna & Italy & $54(55)^{\star}$ & 37 & 69 & 6 & 6 & $-\dagger$ & 一 & $-\dagger$ & 一 \\
\hline
\end{tabular}

^For countries where two centres participated, average attempted suicide rates were computed to make a comparison with the national suicide rates (for Italy only for the age group 15-24 years); tno regional suicide data were available for three centres for 15-24 year olds and for five centres for 15-19 and $20-24$ year olds; $¥$ for two countries no national suicide data were available.

100 000), which represents more than a sixfold difference. In contrast with the findings for female subjects in all but three centres, the highest male attempted suicide rates were found in the age group 20-24 years in all centres.

The suicide rates among male subjects in all centres were much higher than those for female subjects (tables 1 and 2). Relatively high regional suicide rates in 15-24 year olds were found in Szeged and Helsinki, and high national rates in Finland, Norway, Switzerland, and Austria. The highest regional rates in both 15-19 and 20-24 year olds were found in Szeged, Helsinki, and Bern, while national rates were high in 15-19 year olds in Finland and Norway and in 20-24 year olds in Finland, Switzerland, and Norway

CORRELATIONS BETWEEN ATTEMPTED SUICIDE AND SUICIDE RATES

The rank order correlation coefficients between attempted suicide and suicide rates by sex and different age groups are presented in table 3. They were all positive. Overall, the strongest correlations between rates of attempted suicide and suicide, both regionally and nationally, were found among male subjects. There was a significant correlation between attempted suicide rates and both regional and national suicide rates in male subjects in the age group 15-24 years, and a trend that did not reach statistical significance with regional suicide rates in the age group 20-24 years. In fact the correlation coefficients with regional rates for 15-24 year olds and 20-24 year olds were very similar, the latter not reaching statistical significance because the number of centres for which there were five year data was fewer (all centres for the 15-24 year age group but only 10 centres for the five year age bands).

The correlations between attempted suicide rates and suicide rates for female subjects were all positive but non-significant and were lower than those for male subjects in all three age groups at both national and regional levels.

\section{Discussion}

Across the countries of Europe there are positive correlations between rates of attempted suicide and those of suicide in 15-24 year olds of both sexes, but these are more pronounced and only statistically significant in male subjects. There is some indication that the correlation is strongest where data for suicide are from the local areas in which the centres monitoring attempted suicide are based. It is less strong when the correlation is with national suicide rates, although absence of local suicide data for some centres limits this conclusion. Correlations were stronger in both sexes in the 15-24 year age group than when examined in five year age bands, but this was probably because data were available for all centres for the former analyses but only for 10 centres for the latter.

There are considerable differences in the ways in which suicides are registered in the European countries included in this study, with a strong likelihood that misclassification of suicide to other categories of death (for example, undetermined or accidental) is especially noticeable in the young. As this study was based on official suicide statistics we cannot say how inclusion of "hidden suicides", if these

Table 3 Rank order correlations (Spearman) between attempted suicide and suicide rates by sex and age group

\begin{tabular}{|c|c|c|c|c|c|c|}
\hline & $\begin{array}{l}\text { Attempted suicide } \\
\text { rate female } \\
\text { subjects 15-24 }\end{array}$ & $\begin{array}{l}\text { Attempted suicide } \\
\text { rate male subjects } \\
15-24\end{array}$ & $\begin{array}{l}\text { Attempted suicide } \\
\text { rate female } \\
\text { subjects } 15-19\end{array}$ & $\begin{array}{l}\text { Attempted suicide } \\
\text { rate male subjects } \\
15-19\end{array}$ & $\begin{array}{l}\text { Attempted suicide } \\
\text { rate female } \\
\text { subjects } 20-24\end{array}$ & $\begin{array}{l}\text { Attempted suicide } \\
\text { rate male subjects } \\
20-24\end{array}$ \\
\hline $\begin{array}{l}\text { Regional } \\
\quad \text { suicide rate }\end{array}$ & $0.41 \ddagger$ & $0.65 \dagger \neq$ & 0.36 ฯ & $0.37 \uparrow$ & 0.27 ฯ & 0.57 ॠ \\
\hline $\begin{array}{l}\text { National } \\
\quad \text { suicide rate }\end{array}$ & $0.22 \sqrt{ }$ & $0.55+s$ & $0.11 \ddagger$ & $0.29 \ddagger$ & $0.15 \ddagger$ & $0.37 \ddagger$ \\
\hline
\end{tabular}

${ }^{\star} \mathrm{p}<0.09$ (trend); $\uparrow \mathrm{p}<0.02 ; \ddagger$ the correlation is based on the data from 12 centres; $₫$ the correlation is based on the data from all (15) centres; $\uparrow$ the correlation is based on the data from 10 centres. 
KEY POINTS

- Rates of attempted suicide and suicide in 15-24 year olds tend to correlate with each other across countries.

- The correlations are much stronger in male subjects than female subjects.

- Changes in attempted suicide rates in the young (especially males) may be accompanied by changes in suicide rates.

could be identified, might have affected the findings.

Why should the association between suicide and attempted suicide in 15-24 year olds be stronger in male than female subjects? The findings must be interpreted against a background of generally much higher rates of attempted suicide in young female subjects than male subjects and the reverse for suicide. One reason is that the motivation, especially suicidal intent, involved in suicide attempts by young male subjects may show some differences from that of young female subjects, with the behaviour by male subjects being more clearly related to suicide in the sense of showing higher suicidal intent. ${ }^{12}$ On the other hand, such acts by female subjects often involve lower suicidal intent and are more usually associated with motives such as communication of despair and influencing others. A second reason is that the risk of suicide after attempted suicide in the young is much greater in male subjects than female subjects. ${ }^{13}{ }^{14}$

An important potential implication of the findings is that any changes in attempted suicide rates in the young, especially in male subjects, may be accompanied by changes in suicide rates. This is of particular concern in view of the recently reported increase in rates of attempted suicide in the young in some countries. ${ }^{45}$ Confirmation of this will require examination of trends over time in individual centres and countries. This was not possible with the current data because the findings were only for four years, but will become feasible as the data for more years become available.

In conclusion, this study has shown that there is a relation between rates of suicide and attempted suicide in young male subjects in the countries of Europe. This association is much less pronounced in female subjects.

The WHO/EURO Multicentre Study of Parasuicide was initiated by the World Health Organisation. The research for this study in Oxford is supported by the Department of Health of England and Wales. Ella Arensman is supported by a grant from Anglia and Oxford Research and Development Fund. Funding: financial support for coordination of the project was provided by the World Healt Oranisation for the project was obtained in each individual centre. Conflicts of interest: none.

\section{Appendix}

K Hawton, E Arensman, University Department of Psychiatry, Warneford Hospital, Oxford, United Kingdom; D Wasserman, A Hultén, Centre for Suicide Research and Prevention, Karolinska Institute, Stockholm, Sweden; U Bille-Brahe, Unit for Suicidological Research, Odense, Denmark; T Bjerke, Department of Education and Social Science, Lillehammer College, Lillehammer, Norway; P Crepet, Emilia Romagna Health Authority, Rome, Italy; E Deisenhammer, Psychiatrisches Krankenhaus des Landes Tirol, Austria; A Kerkhof, Department of Clinical Psychology, Vrije University Amsterdam, Amsterdam, the Netherlands; D De Leo, Department of Psychiatry, University of Padova, Padova, Italy; K Michel, Psychiatrische Universitätspoliklinik, Bern, Switzerland; A Ostamo, National Public Health Institute, Helsinki, Finland; A Philippe, INSERM, Le Vesinet, France; I Querejeta, Hospital de Guipuzcoa, Servicio de Psiguiatria, San Sebastian, Spain; E Salander-Renberg, Psychiatric Institute, Unversity of Umea, Umea, Sweden; A Schmidtke, Universitäts Nervenklinik, Wurzburg, Germany; B Temesváry, Department of Neurology and Psychiatry, Medical University, Szeged, Hungary.

1 Platt S, Bille-Brahe U, Kerkhof A, et al. Parasuicide in Europe: the WHO/EURO multicentre study on parasuicide. Introduction and preliminary analysis. Acta Psychiatr Scand 1992;85:97-104.

2 Kerkhof AJFM, Schmidtke A, Bille-Brahe U, De Leo D, Lönnqvist J. Attempted suicide in Europe. Findings from the multicentre study of parasuicide by the WHO Regional Office for Europe. Leiden: DSWO Press, 1994

3 Schmidtke A, Bille-Brahe U, De Leo D, et al. Attempted suicide in Europe: rates, trends and sociodemographic characteristics of suicide attempters during the period 1989-1992. Results of the WHO/EURO Multicentre Study on Parasuicide. Acta Psychiatr Scand 1996;93:32738.

4 Hawton K, Fagg J. Deliberate self-poisoning and self-injury in adolescents. A study of characteristics and trends in Oxford, 1976-89. Br F Psychiatry 1992;161:816-23.

5 McLoone P, Crombie IK. Hospitalisation for deliberate self-poisoning in Scotland from 1981 to 1993: Trends in rates and types of drugs used. Br f Psychiatry 1996;169:815 .

6 Diekstra RFW. The epidemiology of suicide and parasuicide. Acta Psychiatr Scand 1993;suppl 371:9-20.

7 Hawton K, Catalan J. Attempted suicide. A practical guide to its nature and management. Oxford: Oxford University Press, 1987

8 Bille-Brahe U, Schmidtke A, Kerkhof AJFM, et al. Background and introduction to the WHO/EURO Multicentre Study on Parasuicide. Crisis 1995;16;72-8.

9 Bille-Brahe U, Andersen K, Wasserman D, et al. The WHO/ EURO Multicentre Study: Risk of parasuicide and the comparability of the areas under study. Crisis 1995;17:3242 .

10 World Health Organisation (WHO). Annual World Health Statistics 1993. Geneva: WHO, 1994.

11 World Health Organisation (WHO). Annual World Health Statistics 1994. Geneva: WHO, 1995.

12 Bancroft JHJ, Skrimshire AM, Simkin S. The reasons people give for taking overdoses. Br f Psychiatry 1976;128: $538-48$

13 Otto U. Suicidal acts by children and adolescents. Acta Psychiatr Scand 1972;suppl 233.

14 Goldacre M, Hawton K. Repetition of self-poisoning and subsequent death in adolescents who take overdoses. $\mathrm{Br} \mathcal{F}$ Psychiatry 1985;146:395-8. 